\title{
Microbial Degradation of Pyridine by Co-culture of Two Newly Isolated Strains, Arthrobacter sp. Strain PDC-1 and Rhodococcus sp. Strain HPD-2
}

Chunhui Hu

Qingdao Agricultural University

Shuxue Zhao

Ocean University of China

Lizhong Guo

Qingdao Agricultural University

Hao Yu ( $\square$ yuhaosunshine@163.com )

Qingdao Agricultural University https://orcid.org/0000-0002-1892-7993

Xi Chen

Ocean University of China

Original article

Keywords: pyridine, microbial degradation, Arthrobacter, Rhodococcus, co-culture, pathway

Posted Date: September 4th, 2020

DOI: https://doi.org/10.21203/rs.3.rs-64856/v1

License: (c) (1) This work is licensed under a Creative Commons Attribution 4.0 International License.

Read Full License 
1 Microbial Degradation of Pyridine by Co-culture of Two Newly

2 Isolated Strains, Arthrobacter sp. Strain PDC-1 and Rhodococcus sp.

3 Strain HPD-2

4

5 Chunhui $\mathrm{Hu}^{1,2 \S}$, Shuxue Zhao ${ }^{1,2 \S}$, Lizhong $\mathrm{Guo}^{3}$, Hao $\mathrm{Yu}^{3 *}$, and $\mathrm{Xi} \mathrm{Chen}^{2 *}$

6

7 1. Central Laboratory of Qingdao Agricultural University, Qingdao Agricultural University,

8 Qingdao, People's Republic of China

9 2. College of Environmental Science and Engineering, Ocean University of China, Qingdao

$10 \quad 266100$, China

11 3. Shandong Provincial Key Laboratory of Applied Mycology, College of Life Sciences, Qingdao

12 Agricultural University, Qingdao, People's Republic of China

14 Running Title: Pyridine degradation by co-cultural strains

§Chunhui Hu and Shuxue Zhao contributed equally to this study.

*Correspondence:

Xi Chen

chenxi@ouc.edu.cn

Mailing address: College of Environmental Scince and Engineering, Ocean University of China, Qingdao 266100, China

$\mathrm{Hao} \mathrm{Yu}$

yuhaosunshine@163.com

Keywords: pyridine, microbial degradation, Arthrobacter, Rhodococcus, co-culture, pathway 
Abstract

Pyridine is one of the most widespread heterocyclic contaminants. Microbial degradation of pyridine seems quite promising for its safety and efficiency. A bacterial consortium, which could use pyridine as the sole source of carbon, nitrogen, was obtained from the petroleum-contaminated soil from Liao River estuarine wetland. Two pyridine degrading strains, designated as PCD-1 and HPD-2, were isolated from the bacterial consortium. PCD-1 was identified as an Arthrobacter, and HPD-2 was identified as the Rhodococcus genus. The effects of $\mathrm{pH}$, temperature, and pyridine concentration were investigated, and the optimum growth conditions for two strains were similar at $\mathrm{pH} 7.0$ and $30^{\circ} \mathrm{C}$. The co-culture of the two strains, CoPD, has better degradation efficiency compared with the individual strain. Haldane's inhibitory growth kinetics equation could be fitted to the growth of co-culture CoPD well for the entire concentration range. The kinetic constants obtained were $\mu_{\max }=0.141 \mathrm{~h}^{-1}, K_{\mathrm{s}}=37.9 \mathrm{mg} / \mathrm{L}$, and $K_{\mathrm{i}}=3830 \mathrm{mg} / \mathrm{L}$. Co-culture CoPD was able to remove more than $98 \%$ pyridine with an initial pyridine concentration of 5,000 mg/L within $120 \mathrm{~h}$.

Strain PCD-1 and HPD-2 have a novel pyridine degradation pathway different from the reported pathways. Major intermediates of pyridine degradation by two strains, including 2,5-pyrroldione, maleic semialdehyde, furanone, and butyrolactone, were identified using LC-MS analysis. CoPD is

a promising tool for the treatment of wastewater containing pyridine, and this study contributes to the knowledge of the pyridine biodegradation by bacterial consortium.

\section{Introduction}

Pyridine and its derivatives are of major concern as carcinogenic, teratogenic, and mutagenic 
priority pollutants (Richards and Shieh, 1986), and is extensively used in industries as solvent and

platform chemical for the synthesis of textiles, pharmaceuticals, agrochemicals and industrial manufacturing (Scriven and Murugan, 1996; Sims et al., 1989). Pyridine is volatile, the hetero-aromatic ring makes it persistent in the environment, and the nitrogen atom gives the hydrophilic properties to pyridine, which makes it better dissolved in water than its carbocyclic analogs. The pyridine and its oxidized derivatives may cause severe health implications (Sun et al., researchers' attention (Bouyarmane et al., 2010; Li et al., 2017; Sims et al., 1989). The existing physicochemical purification methods are not very efficient when they treat nitrogen heterocyclics (Chu et al., 2018; Li et al., 2017). Therefore, the biological degradation of pyridine is considered to be an attractive approach compared with physical or chemical methods. Pyridine degradation by strain(s) individually or immobilized strain(s) on fixing agents in bioreactors is a subject of a good deal of research (Lin et al., 2010; Uma and Sandhya, 1998; Wen et al., 2013). In general, the pyridine strain with high pyridine degrading capacity will enhance the pyridine degradation capacity in the bioreactor through bioaugmentation (Jin et al., 2020; Liu et al., 2020; Lodha et al., 2008; Uma and Sandhya, 1998; Wen et al., 2013; Xue et al., 2020; Zhang et al., 2018). Therefore, the study of pyridine degrading strain(s) is one of the core issues of pyridine removal. To data, several strains have been isolated from the environment which could use pyridine as the sole source of carbon and nitrogen, including Achromobacter, Alcaligenes, Arthrobacter, Azparcus, Bacillus, Gprdpmoa, Micrococcus, Nocardioides, Nocardia, Paracoccus, Pseudomonas, Rhizobium, Rhodococcus, Rhodopseudomonas, Shewanella, Shinella et al (Jin et al., 2020; Liu et al., 2020; Mathur et al., 2008; Wang et al., 2018; Xue et al., 2020; Zhang et al., 2018). The isolates 
presented different degradation capacities. Some strains could grow with $5500 \mathrm{mg} / \mathrm{L}$ initial concentration of pyridine and completely removed the pyridine within 192 hours (Stobdan et al., 2008), while some strain could bear only $20 \mathrm{mg} / \mathrm{L}$ pyridine and the degradation efficiency was dropped significantly with 30-50 mg/L pyridine (Kaiser and Bollag, 1992; Lodha et al., 2008). Therefore, the high pyridine tolerance and efficient pyridine degradation strain still to be elucidated. other strains. All the elements will influence the pyridine degradation (Chandra et al., 2009). The pyridine degradation capability will be enhanced by adding some nutrients such as glucose as well as other pollutants such as phenol (Bai et al., 2009; Quan et al., 2017; Sun et al., 2011). Besides, other elements such as the products of pyridine degradation, ammonia, will also affect the pyridine degradation (Qiao and Wang, 2010; Wang et al., 2018). Pyridine degradation will also be influenced by fixation methods, as well as bioreactor and zeolite (Bai et al., 2010; Wen et al., 2013). co-cultures for pyridine degradation will help us to elucidate the interaction between strains and the adaptation to the environment.

In this study, a pyridine-degrading bacterial consortium was obtained and two single strains with pyridine degrading capacity were isolated from the bacterial consortium. The degradation properties of the co-culture of the two isolates were investigated. The growth kinetics was 
investigated for better understanding the pyridine degradation. In addition, the metabolic products of the two strains were also analyzed.

\section{Materials and methods}

99

100

101

102

103

104

105

106

107

108

109

110

111

112

113

\section{Chemicals}

Pyridine, 2-hydroxypyridine, 3-hydroxypyridine, 4-hydroxypyridine and monocarboxylic pyridines were of analytical grade and purchased from Aladdin (Shanghai, China). Methanol and formic acid were LC-MS grade and purchased from Aladdin (Shanghai, China) and ThermoFisher, respectively. All other chemicals used in this study were of AR grade with more than 99\% purity and purchased from commercial manufacturers.

\section{Strains and cultivation conditions}

Pyridine-degrading bacterial consortium was isolated from petroleum-contaminated soil taken near the Liao River estuarine wetland. Single colonies were obtained by plating the bacterial consortium on the MSM agar plate with particular substrates as previously described (Yu et al., 2018). The bacterial consortium/strains were grown in $250 \mathrm{~mL}$ Erlenmeyer flasks containing $50 \mathrm{~mL}$ MSM with different concentrations of pyridine unless otherwise stated. MSM was sterilized by autoclaving at $121^{\circ} \mathrm{C}$ for $20 \mathrm{~min}$. Pyridine or other pyridinic compounds were added after filtered by a $0.22 \mu \mathrm{m}$ sterile syringe filter (Jinteng, China). The strains were incubated at $30^{\circ} \mathrm{C}$ on a rotary shaker (150 rpm). Isolated strains were identified by $16 \mathrm{~S}$ rRNA gene sequence analysis. The genomes of bacteria were extracted using Ezup pillar bacterial genome DNA extraction kit (Sangon Biotech, China) followed the instruction for Gram-positive strains. The 16S rRNA gene was amplified using primers $27 \mathrm{~F}$ and $1492 \mathrm{R}$. The PCR reaction was performed using the following 
117 cycling conditions: $95^{\circ} \mathrm{C}$ for $5 \mathrm{~min}, 35$ cycles of $95^{\circ} \mathrm{C}$ for $30 \mathrm{~s}, 58^{\circ} \mathrm{C}$ for $30 \mathrm{~s}$ and $72^{\circ} \mathrm{C}$ for $90 \mathrm{~s}$,

118 followed by $72^{\circ} \mathrm{C}$ for $10 \mathrm{~min}$. Nucleotide sequences similarities for phylogenetic analysis were

119 obtained from the LPSN database. Phylogenetic analysis was performed by MEGA6.0 software.

\section{Biodegradation of pyridine by Co-culture or isolated strains}

121 In order to understand the degradation and growth pattern of bacterial co-culture or isolates, the effects of $\mathrm{pH}$, temperature, and substrate concentration were determined in MSM. The samples were withdrawn at particular time interval and analyzed for bacterial growth. The cells were then removed by centrifugation at $10,000 \times \mathrm{g}, 4^{\circ} \mathrm{C}$ for $5 \mathrm{~min}$, and the supernatant was transferred to a new centrifugation tube for further analysis. Control experiments were carried out using autoclaved MSM with the same pyridine concentration without microorganisms to determine the

loss of substrate due to evaporation.

$$
\text { Degradation rate }=\left(1-\frac{\text { pyridine concentration in the sample }}{\text { pyridine concentration in the control }}\right) \times 100
$$

\section{$128 \quad$ Kinetics models}

In order to understand the growth pattern of the co-culture. The effects of substrate concentration were performed in MSM with different concentrations of pyridine. In the batch system, the specific growth rate $(\mu)$ was defined as

$$
\frac{d X}{d t}=\mu X-K_{d} X
$$

$X$ is cell concentration (OD600nm), $\mu$ is a specific growth rate of the cell $\left(\mathrm{h}^{-1}\right)$, and $K_{d}$ is the endogenous decay coefficient $\left(\mathrm{h}^{-1}\right)$. At the exponential growth phase, the $K_{d}$ could be neglected, and the equation (1) was reduced to

$$
\frac{d X}{d t}=\mu X
$$

137 The value of $\mu$ was determined at the exponential phase of the growth curve according to equation 
Two models were used to fit the experimental data obtained from the batch experiments. Monod equation (3).

$$
\mu=\frac{\mu_{\max } \mathrm{S}}{K_{S}+\mathrm{S}}
$$

Haldane inhibitory growth model represents the growth kinetics of an inhibitory compound such as pollutants (Kumar et al., 2005; Park et al., 2002) as equation (4).

$$
\mu=\frac{\mu_{a p p} * S_{0}}{K_{s}+S_{0}+\left(\frac{S_{0}^{2}}{K_{i}}\right)}
$$

where $S_{0}$ denotes the concentration of pyridine $(\mathrm{mg} / \mathrm{L})$.

147 The true maximum specific growth rate in the Haldane model occurred when $d_{\mu} / d_{\mathrm{S}}=0$ as below

148 (Christen et al., 2012):

$$
S_{m}=\sqrt{K_{s} K_{i}}
$$

The maximum specific growth rate can be obtained by replacing $S_{\mathrm{m}}$ in Eq. (4).

The values of the kinetic parameters were obtained from non-linear fitting using Origin software.

\section{Intermediates identification and phylogenetic analysis}


160 Growth was monitored spectrophotometrically by measuring the absorbance at wavelength $600 \mathrm{~nm}$

161 (OD600). Pyridine concentration was monitored by high-performance liquid chromatography

162 (HPLC) (Waters Alliance HPLC, USA) equipped with a column of Waters Spherisorb ODS2 (4.6 $\mathrm{mm} \times 250 \mathrm{~mm})$ and a PAD detector. The mobile phase was $70 \%(\mathrm{v} / \mathrm{v})$ methanol and $30 \% 0.05 \%$ $(\mathrm{w} / \mathrm{v})$ formic acid at a flow rate of $1 \mathrm{~mL} / \mathrm{min}$. The signal of $265 \mathrm{~nm}$ was monitored to calculate the pyridine concentration. The supernatant of the samples was treated by adding two-volume of methanol. The samples were precipitated at $4{ }^{\circ} \mathrm{C}$ for $5 \mathrm{~min}$, centrifuged at $10,000 \times \mathrm{g}$ for $2 \mathrm{~min}$, and then filtered by a $0.22 \mu \mathrm{m}$ sterile syringe filter.

To identify the degradation intermediates of the two isolated strains, samples from resting cell reactions were analyzed by LC-MS/MS. LC-MS/MS analysis was performed with UltiMate3000 UHPLC system (Thermo Fisher, USA) equipped with Orbitrap Fusion Lumos mass spectrometer and an electrospray ionization source (ESI), using reverse-phase column (Agilent ZORBAX RRHD Eclipse Plus $95 \AA \mathrm{C} 18(2.1 \times 100 \mathrm{~mm}, 1.8 \mu \mathrm{m})$ at $30^{\circ} \mathrm{C}$. The mobile phase is $70 \%(\mathrm{v} / \mathrm{v})$ methanol and $30 \% 0.05 \%(\mathrm{w} / \mathrm{v})$ formic acid at a flow rate of $0.2 \mathrm{~mL} / \mathrm{min}$. Both positive and negative electrospray ionization analysis with the continuous full scanning from $\mathrm{m} / \mathrm{z} 50$ to 500 were performed. The data were analyzed using Compound Discovery software (Thermo Fisher).

Results

\section{Strains identification}

A bacterial consortium, which could utilize pyridine as the sole source of carbon and nitrogen, was isolated from petroleum-contaminated soil in Liao River estuarine wetland. A series of pyridinic 
compounds were provided as growth substrates for this bacterial consortium, respectively. The bacterial consortium could grow with pyridine and 2-hydroxypyridine, but it could not use 3-hydroxypyridine, 4-hdyroxypyridine, picolinic acid, nicotinic acid, or isonicotinic acid as the growth substrate. After serial dilution, one dominant colony was observed on the MSM + pyridine agar plate. This strain was isolated and the 16S rRNA gene was sequenced. This strain was designated as PCD-1 and classified as Arthrobacter based on the 16S rRNA gene and morphology properties. However, PCD-1 could only grow with pyridine, it could not grow with 2-hydroxypyridine. Then, this bacterial consortium was cultivated with 2-hydroxypyridine as the sole substrate for 3 cycles. After serial dilution, one dominant colony was isolated from the plate. This strain, namely HPD-2, was identified as Rhodococcus sp. Strain HPD-2 could grow with both pyridine and 2-hydroxypyridine as the substrate.

\section{Effect of temperature and pH on the degradation of pyridine}

The growth and pyridine degradation were assessed at different $\mathrm{pH}$ and temperature values for both Arthrobacter sp. PCD-1 and Rhodococcus sp. HPD-2. The results revealed that strain PCD-1 could grow well at a temperature ranging from $25^{\circ} \mathrm{C}$ to $37^{\circ} \mathrm{C}$, and showed the highest growth rate at $30^{\circ} \mathrm{C}$ (Fig. 1a). Strain PCD-1 grew well at $\mathrm{pH}$ values ranging from 7.0 to 9.0 and showed the highest growth rate at $\mathrm{pH} 8.0$ (Fig. 1b). However, there was almost no growth at $\mathrm{pH} 6.0$ or $\mathrm{pH} 10.0$

for strain PCD-1. The optimum $\mathrm{pH}$ values were observed to be 7.0-9.0 for Rhodococcus sp. HPD-2. The lag phase at $\mathrm{pH} 7.0$ was slightly shorter than those at $\mathrm{pH} 8.0$ and 9.0, and the maximum cell density at $\mathrm{pH} 9.0$ was a little bit higher than those at $\mathrm{pH} 7.0$ and 8.0 (Fig. 1c). The optimum temperature for strain $\mathrm{HPD}-2$ was $30^{\circ} \mathrm{C}$ (Fig. 1d). The results revealed that both strains could grow 
very similar. Rhodococcus sp. strain HPD-2 could use both pyridine and 2-hydroxypyridine as the

growth substrate. 2-Hydroxypyridine is a better growth substrate for strain HPD-2 than pyridine

(Fig. 2a). The culture color of strain HPD-2 with pyridine was white, while the culture color with

2-hydroxypyridine was yellow-brown (Fig. 2b).

\section{Growth kinetics of co-culture}

Both Arthrobacter sp. PCD-1 and Rhodococcus sp. HPD-2 could use pyridine as the growth

substrate, thus the two strains were re-mixed to form the co-culture CoPD. The growth with

co-culture and individual strain were compared. It was observed that the growth of individual

strain Arthrobacter sp. PCD-1 and Rhodococcus sp. HPD-2 was slower compared to the co-culture

of the two strains (Fig. 3). Under optimal conditions, the growth of co-culture, CoPD, was

measured with different concentrations (from $100 \mathrm{mg} / \mathrm{L}$ to $5000 \mathrm{mg} / \mathrm{L}$ ) of pyridine. The co-culture

could grow in all the tested concentrations. The lag phase with high initial pyridine concentration

( $\geqq 2000 \mathrm{mg} / \mathrm{L}$ ) was significantly prolonged, which may be due to substrate inhibition (Fig. 4a).

Figure 4 shows a typical trend that the value of specific growth rate increases with the increase of

initial pyridine concentration up to a certain concentration level, then it begins to decrease with the

increase of pyridine concentration. The results confirmed that pyridine was an inhibitory substrate.

The growth kinetics are essential for understanding the capacities of the bacteria for pollutant

degradation. Therefore, the determination of the growth kinetics of microorganisms has been one

of the main issues in these studies. Two growth models were used to describe the growth rate of

co-culture CoPD for a wide pyridine concentration. In general, the Haldane's growth model is used

to describe the growth kinetics data of an inhibitory compound. The correlation coefficients $\left(R^{2}\right)$ 
growth with pyridine(Fig. 4b). The value of maximum specific growth rate, $\mu_{\max }$, is $0.141 \mathrm{~h}^{-1}$ at 380

$\mathrm{mg} / \mathrm{L}\left(S_{\mathrm{m}}\right)$ initial pyridine concentration, and the substrate inhibition coefficient, $K_{\mathrm{i}}$, is $3830 \mathrm{mg} / \mathrm{L}$.

The value of the substrate half-saturation coefficient, $K_{\mathrm{s}}$, is $37.9 \mathrm{mg} / \mathrm{L}$.

in Figure 4c, d. Co-culture CoPD could completely degrade all the tested pyridine concentrations

ranging from 100 to $5000 \mathrm{mg} / \mathrm{L}$ to an efficiency of $>98 \%$.

\section{Degradation profile of pyridine by two strains}

To investigate the degradation pattern of pyridine by two strains, resting cell reactions were

2/3/4-carboxypyridine. The samples were analyzed using HPLC, and the results showed that strain

PCD-1 could only convert pyridine, while strain HPD-2 could only convert pyridine and

2-hydroxypyridine. A single peak of intact pyridine compound was observed at a retention time of

$3.56 \mathrm{~min}$ in the HPLC chromatogram, and the peak disappeared gradually with the reaction time.

However, no new peak could be detected in the HPLC signal.

The intermediates were then identified using high-resolution accurate mass measurements by

Orbitrap Fusion Lumos (Thermo Scientific) (Fig. 5). Two main intermediates detected in the

resting cell reaction of strain PCD-1 were presented. The base peak of M1 with $\mathrm{m} / \mathrm{z}$ of 98.06020 in

the positive ion ESI mass spectrum in Figure 5a was identified as 2,5-pyrrolidione, which matched

with formula $\mathrm{C}_{4} \mathrm{H}_{3} \mathrm{NO}_{2}$. Compounds $\mathrm{M} 2$ and $\mathrm{M} 3$ which were detected with an $\mathrm{m} / z$ of 87.08062 and

101.09622, respectively, were identified as butyrolactone $\left(\mathrm{C}_{4} \mathrm{H}_{6} \mathrm{NO}_{2}\right)$ and maleic semialdehyde

$\left(\mathrm{C}_{4} \mathrm{H}_{4} \mathrm{NO}_{3}\right)$, each. For strain HPD-2, the intermediate M2 was also detected in the LC-MS spectra 
as shown in Figure 5c. Besides, a peak of M4 with an $m / z$ of 85.02858 in the positive ion ESI mass spectrum was identified as furanone $\left(\mathrm{C}_{4} \mathrm{H}_{4} \mathrm{O}_{2}\right)$ as shown in Figure $5 \mathrm{~d}$. It can be seen that $\mathrm{M} 2$ could be produced by both strain PCD-1 and HPD-2. Besides, M3 and M4 are the substrate and product of a catalyzing reaction. Thus, it can be proposed that the two strains use similar pyridine degradation pathway, which was proposed as Figure 6 based on the intermediates' identification and previous studies.

\section{Discussions}

Environmental pollution has become one of the serious problems in modern society. Millions of tons of pollutants are discharged every day, among which pyridine and its derivatives are one of the most distributed contaminants. Microbial bioremediation is a promising method for pyridine removal from the environment. In this study, two newly isolated strains, Arthrobacter sp. PCD-1 and Rhodococcus sp. HPD-2, which could use pyridine as the sole source of carbon and nitrogen, were isolated from the petroleum pollutant soil in Liao River estuarine wetland. The two isolates were mixed to form bacterial consortium CoPD. Both Arthrobacter and Rhodococcus were widely studied because of their properties of degradation for recalcitrant aromatic and pyridinic compounds (Arora and Sharma, 2015; Presentato et al., 2018; Ren et al., 2018; Sengupta et al., 2019; Sun et al., 2011; Yao et al., 2012; Zefirov et al., 1994). Compared with reported Arthrobacter and Rhodococcus, the co-culture CoPD showed more excellent pyridine degradation capacity. Besides, CoPD showed better pyridine biodegradation capacity than each of the two isolated strains. CoPD was able to completely degrade pyridine at an initial concentration up to 5,000 mg/L. This is a high reported pyridine concentration among all the reported pyridine degrading bacteria, 
calcium alginate gel beads immobilized Pimelobacter sp. could remove nearly $90 \%$ pyridine at an

271

272

273

274

275

276

277

278

279

280

281

282

283

initial concentration of $10000 \mathrm{mg} / \mathrm{L}$ within 164 h (Lee et al., 1994). Gordonia terrea IIPN1 could completely remove $5530 \mathrm{mg} / \mathrm{L}$ pyridine within 192 days (Stobdan et al., 2008). Achromobacter sp.

DN-06 could grow with up to $4,300 \mathrm{mg} / \mathrm{L}$ pyridine and the $\mu_{\max }$ fitting to Haldane's inhibitory growth kinetics was $0.161 \mathrm{~h}^{-1}$, similar to that of co-culture CoPD (Deng et al., 2011). The excellent pyridine capacity of CoPD might due to the efficient pyridine catalyzing enzymes and the high pyridine tolerance. The growth kinetics studies have proved that high pyridine concentration will inhibit the growth of co-culture CoPD. It has been observed that the lag phase in high pyridine concentration is long. This was probably due to the RNA and protein involved in pyridine degradation that should be synthesis in this phase, therefore high inoculation will reduce the lag phase (Lee et al., 1994). The toxic and inhibitory effect toward the bacterial cells is another reason for the long lag phase. Pyridine is volatile compounds, and the concentration will decrease during the cultivation in both of the control and inoculated culture, especially with high pyridine concentration. At high concentrations, the decrease of pyridine concentration in early-stage mainly due to evaporation. The growth of the strain after a long lag phase may be due to the pyridine concentration has decreased to a relatively low concentration by volatilization. Nevertheless, the co-culture CoPD was able to tolerate and grow on pyridine up to $5000 \mathrm{mg} / \mathrm{L}$.

It is important to analyze the degradation pathway of the pyridine, because microbial degradation may produce some carcinogenic intermediates. Several different pathways have been investigated for microbial degradation of pyridine (Khasaeva et al., 2011; Shukla, 1984; Shukla and Kaul, 1986; Wang et al., 2018; Zefirov et al., 1994). The reported microbial degradation pathways could be classified into two different strategies. One strategy is hydroxylation strategy, in 
which a hydroxylate pyridinic intermediate, such as 2-hydroxypyridine, 2,5-dihydroxypyridine,

least two hydroxyl groups were added into the pyridine-ring, which subsequently undergo ring

cases, the cultures of strain have no color and the intermediates could not be detected by the HPLC analysis with an ultraviolet detector.

Four degradation intermediates were identified in the present study, including 2,5-pyrrolidione, 
accumulated. Moreover, the co-culture CoPD could not grow with pyridine $N$-oxide. The results indicated that strain PCD-1 and HPD-2 use dehydrogenation strategy to degrade pyridine.

Combined with the analysis result of Compound Discovery software,we proposed that the two

The better pyridine degradation capacity for CoPD compared with individuals indicated that of pyridine degradation and tolerance.

\section{Declaration}

Ethics approval and consent to participate: This article does not contain any studies with human 
336 Consent for publication: We are very pleasure to agree the paper to be published in AMB

337 Express. The Author grants the Publisher the sole and exclusive license of the full copyright in the

338 Contribution, which license the Publisher hereby accepts. The Author declares that any person

339 named as co-author of the contribution is aware of the fact and has agreed to being so named.

340 Availability of data and material: The nucleotide sequence data for strain PCD-1 and HPD-2

341 have been submitted to the GenBank and EMBL nucleotide sequence databases under accession

342 number MK053924 and MK208707, respectively.

343 Competing interests: The authors declare that the research was conducted in the absence of any

344 commercial or financial relationships that could be construed as a potential conflict of interest.

345 Funding: This study was funded by Shandong provincial Natural Science Foundation

346 (ZR2016CQ06) and Qingdao Agricultural University Scientific Research Foundation

347 (6631119047).

348 Author Contribution: $\mathrm{CH}, \mathrm{SZ}, \mathrm{XC}$, and $\mathrm{HY}$ performed the experiments. $\mathrm{CH}, \mathrm{XC}$, and $\mathrm{HY}$ analyzed the data. XC, LG and HY provided materials, conceived the project and wrote the manuscript.

Acknowledgements: Not applicable 


\section{References}

Arora PK, Sharma A (2015) New metabolic pathway for degradation of 2-nitrobenzoate by Arthrobacter sp. SPG. Front Microbiol 6:551

Bai Y, Sun Q, Xing R, Wen D, Tang X (2010) Removal of pyridine and quinoline by bio-zeolite composed of mixed degrading bacteria and modified zeolite. J Hazard Mater 181:916- 922

Bai Y, Sun Q, Zhao C, Wen D, Tang X (2009) Aerobic degradation of pyridine by a new bacterial strain, Shinella zoogloeoides BC026. J Ind Microbiol Biotechnol 36:1391- 1400

Bouyarmane H, El Asri S, Rami A, Roux C, Mahly MA, Saoiabi A, Coradin T, Laghzizil A (2010) Pyridine and phenol removal using natural and synthetic apatites as low cost sorbents: influence of porosity and surface interactions. J Hazard Mater 181:736- 741

Chandra R, Bharagava RN, Kapley A, Purohit HJ (2009) Isolation and characterization of potential aerobic bacteria capable for pyridine degradation in presence of picoline, phenol and formaldehyde as co-pollutants. World J Microb Biot 25:2113-2119

Chandra R, Yadav S, Bharagava RN (2010) Biodegradation of pyridine raffinate by two bacterial co-cultures of Bacillus cereus (DQ435020) and Alcaligenes faecalis (DQ435021). World J Microb Biot 26:685- 692

Christen P, Vega A, Casalot L, Simon G, Auria R (2012) Kinetics of aerobic phenol biodegradation by the acidophilic and hyperthermophilic archaeon Sulfolobus solfataricus 98/2. Biochem Eng $J$ 62:56- 61

Chu L, Yu S, and Wang J (2018) Degradation of pyridine and quinoline in aqueous solution by gamma radiation. Radiat Phys Chem 144:322-328

Deng X, Wei C, Ren Y, Chai X (2011) Isolation and identification of Achromobacter sp. DN-06 and evaluation of its pyridine degradation kinetics. Water Air Soil Pollut 221:365- 375

Kaiser JP, Bollag JM (1992) Influence of soil inoculum and redox potential on the degradation of several pyridine derivatives. Soil Biol Biochem 24:351-357

Khasaeva F, Vasilyuk N, Terentyev P, Troshina M, Lebedev AT (2011) A novel soil bacterial strain degrading pyridines. Environ Chem Lett 9:439- 445

Kumar A, Kumar S, Kumar S (2005) Biodegradation kinetics of phenol and catechol using Pseudomonas putida MTCC 1194. Biochem Eng J 22:151- 159

Jin T, Bai B, Yu X, Ren J, Liu R, Bai F, Zhang H (2020) Degradation of pyridine by a novel bacterial strain, Sphingobacterium multivorum JPB23, isolated from coal-coking wastewater. Desalin Water Treat 188:45-97

Lee ST, Rhee SK, Lee GM (1994) Biodegradation of pyridine by freely suspended and immobilized Pimelobacter sp. Appl Microbiol Biotechnol 41:652- 657

Li Y, Yi R, Yi C, Zhou B, Wang H (2017) Research on the degradation mechanism of pyridine in drinking water by dielectric barrier discharge. J Environ Sci 53:238- 247

Lin Q, Donghui W, Jianlong W (2010) Biodegradation of pyridine by Paracoccus sp. KT-5 immobilized on bamboo-based activated carbon. Bioresour Technol 101:5229- 5234

Liu Y, Zhang Q, Lv Y, Ren R (2020) Pyridine degradation characteristics of a newly isolated bacterial strain and its application with a novel reactor for the further treatment in pyridine wastewater. Process Biochem 95:64-70

Lodha B, Bhadane R, Patel B, Killedar D (2008) Biodegradation of pyridine by an isolated bacterial consortium/strain and bio-augmentation of strain into activated sludge to enhance pyridine biodegradation. Biodegradation 19:717-723 
Mathur AK, Majumder CB, Chatterjee S, Roy P (2008) Biodegradation of pyridine by the new bacterial isolates $S$. putrefaciens and B. sphaericus. J Hazard Mater 157:335-343

Park C, Kim TH, Kim S, Lee J, Kim SW (2002) Biokinetic parameter estimation for degradation of 2,4,6-trinitrotoluene (TNT) with Pseudomonas putida KP-T201. J Biosci Bioeng 94:57- 61

Presentato A, Cappelletti M, Sansone A, Ferreri C, Piacenza E, Demeter MA, Crognale S, Petruccioli M, Milazzo G, Fedi S, Steinbüchel A, Turner RJ, Zannoni D (2018) Aerobic growth of Rhodococcus aetherivorans $\mathrm{BCP} 1$ using selected naphthenic acids as the sole carbon and energy sources. Front Microbiol 9:672

Qiao L, Wang JL (2010) Microbial degradation of pyridine by Paracoccus sp. isolated from contaminated soil. J Hazard Mater 176:220-225

Quan J, Li Y, Sun Q, Zhou J (2017) Co-metabolism degradation of pyridine with glucose in sequencing batch biofilm reactor (SBBR). Nat Environ Pollut Technol 16:479

Ren L, Jia Y, Zhang R, Lin Z, Zhen Z, Hu H, Yan Y (2018) Insight into metabolic versatility of an aromatic compounds-degrading Arthrobacter sp. YC-RL1. Front Microbiol 9:2438

Richards DJ, Shieh WK (1986) Biological fate of organic priority pollutants in the aquatic environment. Water Res 20:1077- 1090

Scriven EF, Murugan R (1996) Kirk-Othmer Encyclopedia of Chemical Technology: Pyridine and pyridine derivatives. Wiley Online Library

Sengupta K, Swain MT, Livingstone PG, Whitworth DE, Saha P (2019) Genome sequencing and comparative transcriptomics provide a holistic view of 4-nitrophenol degradation and concurrent fatty acid catabolism by Rhodococcus sp. Strain BUPNP1. Front Microbiol 9:3209

Shukla O (1984) Microbial transformation of pyridine compounds. Proc Ind Acad Sci Chem Sci 93:1143- 1153

Shukla OP, Kaul SM (1986) Microbiological transformation of pyridine $N$-oxide and pyridine by Nocardia sp. Can J Microbiol 32:330-341

Sims GK, O'Loughlin EJ, Crawford RL (1989) Degradation of pyridines in the environment. Crit Rev Env Sci Tec 19:309-340

Stobdan T, Sinha A, Singh RP, Adhikari DK (2008) Degradation of pyridine and 4-methylpyridine by Gordonia terrea IIPN1. Biodegradation 19:481-487

Sun J, Xu L, Tang Y, Chen F, Liu W, Wu X (2011) Degradation of pyridine by one Rhodococcus strain in the presence of chromium (VI) or phenol. J Hazard Mater 191:62- 68

Sun J, Xu L, Tang Y, Chen F, Zhao J, Wu X (2013) Bacterial pyridine hydroxylation is ubiquitous in environment. Appl Microbiol Biotechnol 98:455-464

Tang H, Wang L, Wang W, Yu H, Zhang K, Yao Y, Xu P (2013) Systematic unraveling of the unsolved pathway of nicotine degradation in Pseudomonas. PLoS Genet 9:e1003923

Uma B, Sandhya S (1998) Kinetics of pyridine degradation along with toluene and methylene chloride with Bacillus sp. in packed bed reactor. Bioproc Eng 18:303- 305

Wang J, Jiang X, Liu X, Sun X, Han W, Li J, Wang L, Shen J (2018) Microbial degradation mechanism of pyridine by Paracoccus sp. NJUST30 newly isolated from aerobic granules. Chem Eng J 344:86- 94

Wen D, Zhang J, Xiong R, Liu R, Chen L (2013) Bioaugmentation with a pyridine-degrading bacterium in a membrane bioreactor treating pharmaceutical wastewater. $J$ Environ $S c i$ 25:2265-2271

Xue L, Hu W, Feng C, Chen N, Chen H, Hu Z (2020) Enhancement and mechanism of 

188:212-222

Yao Y, Tang H, Ren H, Yu H, Wang L, Xu P (2012) Genome sequence of a nicotine-degrading strain of Arthrobacter. J Bacteriol 194:5714-5715

Yu H, Tang H, Zhu X, Li Y, Xu P (2015) Molecular mechanism of nicotine degradation by a newly isolated strain, Ochrobactrum sp. strain SJY1. Appl Environ Microbiol 81:272-281

Yu H, Zhao S, Lu W, Wang W, Guo L (2018) A novel gene, encoding 3-aminobenzoate 6-monooxygenase, involved in 3-aminobenzoate degradation in Comamonas sp. strain QT12. Appl Microbiol Biotechnol 102:4843-4852

Zefirov NS, Agapova SR, Terentiev PB, Bulakhova IM, Vasyukova NI, Modyanova LV (1994) Degradation of pyridine by Arthrobacter crystallopoietes and Rhodococcus opocus strains. FEMS Microbiol Lett 118:71- 74

Zhang Y, Zhang Y, Xiong J, Zhao Z, Chai T (2018) The enhancement of pyridine degradation by Rhodococcus KDPy1 in coking wastewater. FEMS. Microbiol. Lett. 366:1 
Figure 1. The temperature and pH influence on PCD-1 and HPD-2 growth were performed

in MSM with $1000 \mathrm{mg} / \mathrm{L}$ pyridine. (a) Effects of temperature for growth of strain PCD-1; (b) SD.

Figure 2 Growth of Rhodococcus sp. strain HPD-2 with $1000 \mathrm{mg} / \mathrm{L}$ pyridine and $1000 \mathrm{mg} / \mathrm{L}$ replicates $\pm \mathrm{SD}$.

Figure 3 Growth of co-culture CoPD and the individual two strains in MSM with $1000 \mathrm{mg} / \mathrm{L}$

pyridine. Each value is the mean from three parallel replicates $\pm \mathrm{SD}$.

Figure 4 Growth kinetics of co-culture. (a) Effects of pyridine concentration on the growth of

co-culture of strain PCD-1 and HPD-2; (b) Haldane's inhibition growth model fitted to results of

batch growth experimental data to determine bio-kinetics parameters. (c, d) Effects of initial pyridine concentration on pyridine degradation (c) and degradation rate (d) of co-culture. Each value is the mean from three parallel replicates $\pm \mathrm{SD}$.

Figure 5 LC-MS analysis of pyridine degradation intermediates of Arthrobacter sp. PCD-1 (a,

b) and Rhodococcus sp. HPD-2 (c, d).

Figure 6 Proposed microbial pyridine degradation pathways. (a) The hydroxylation strategy of pyridine degradation; (b) The dehydrogenation strategy of pyridine degradation. The red structural 
a

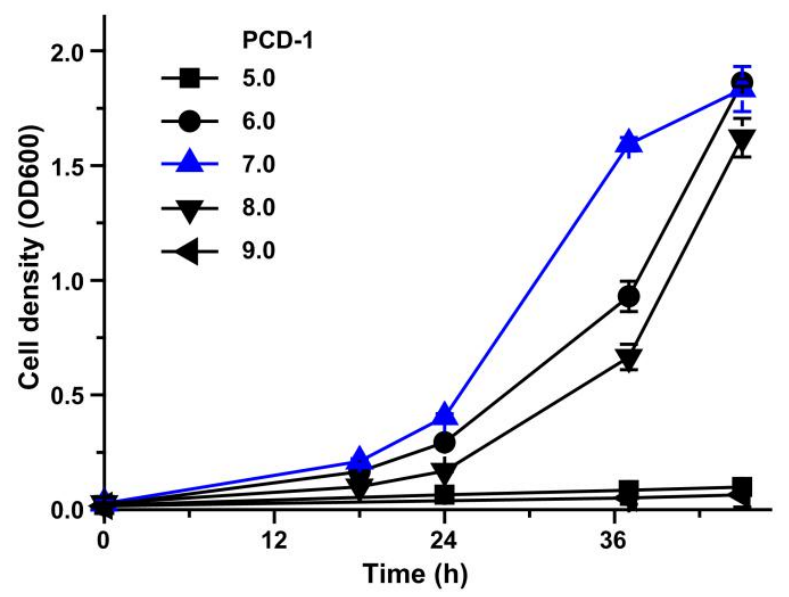

C

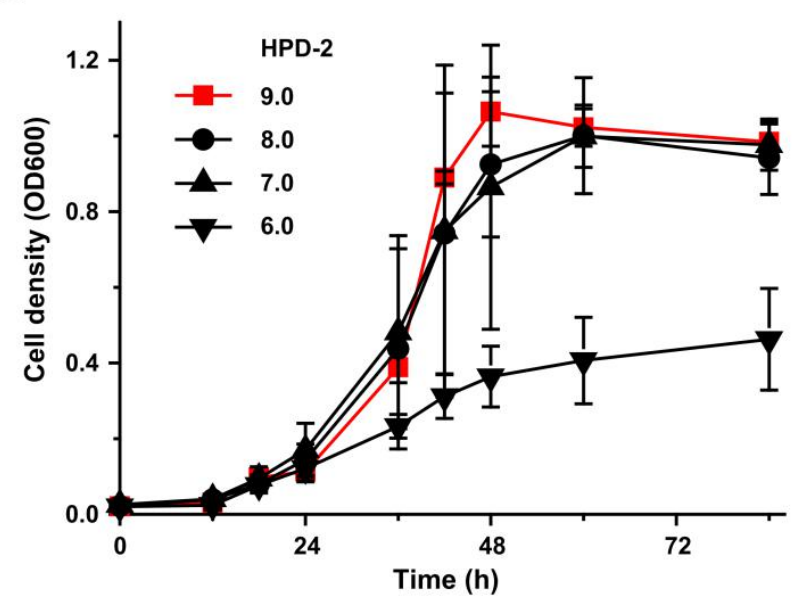

b

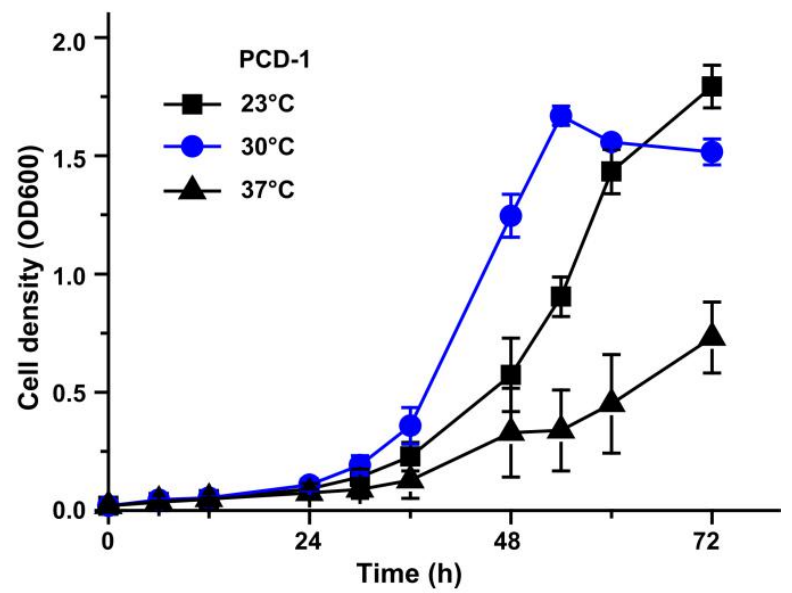

d

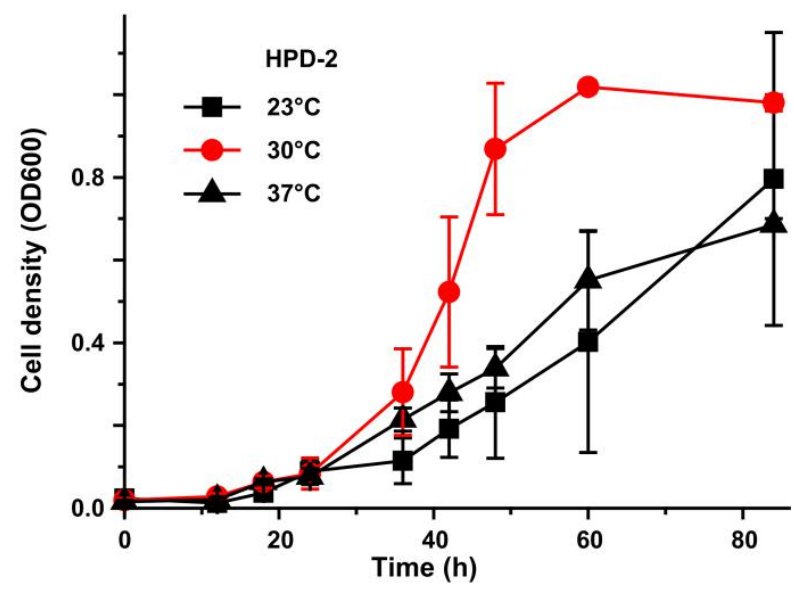


a

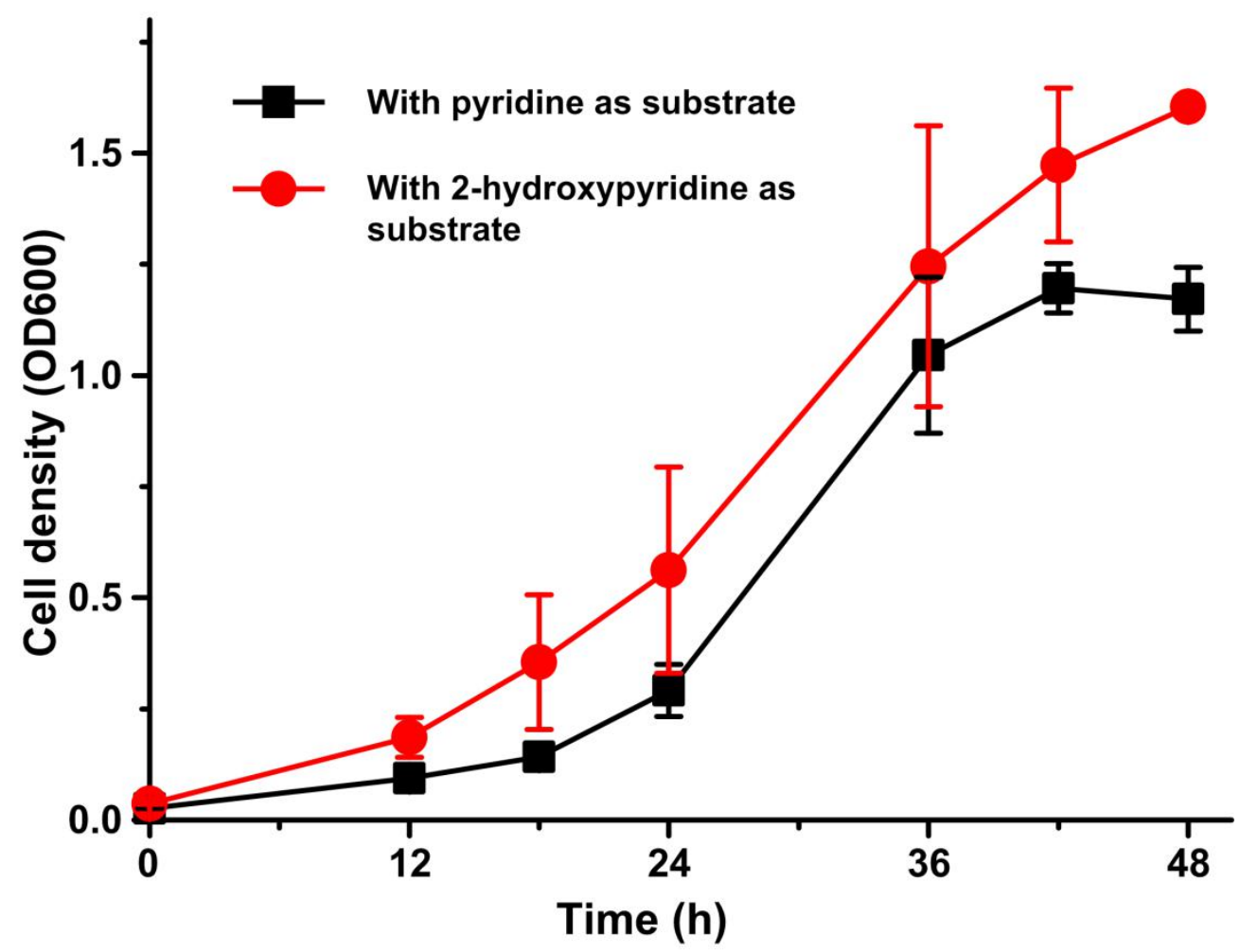

b

Strain HPD-2:

Cultivated with

pyridine
Strain HPD-2:

Cultivated with

2-hydroxypyridine 
$491 \quad$ Figure 3

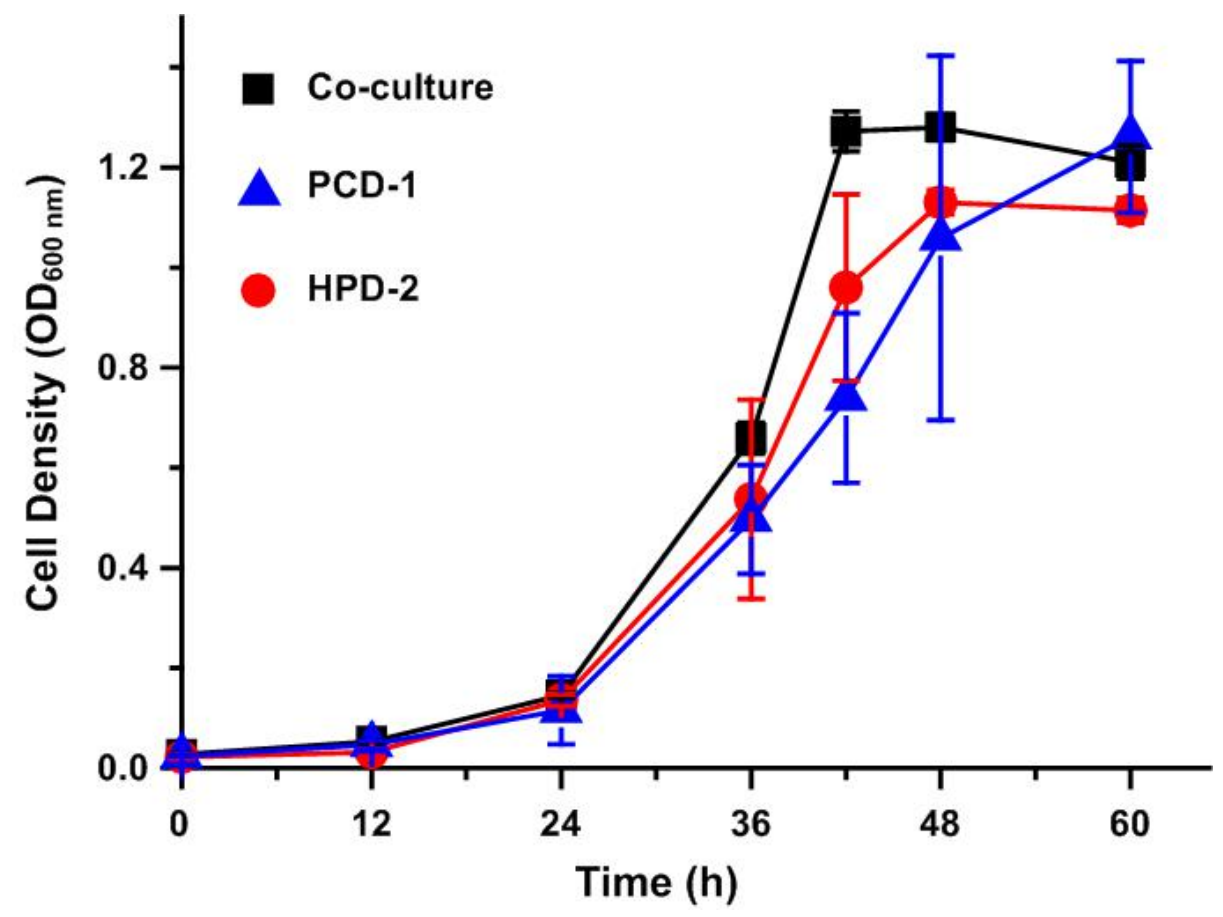

493 
a

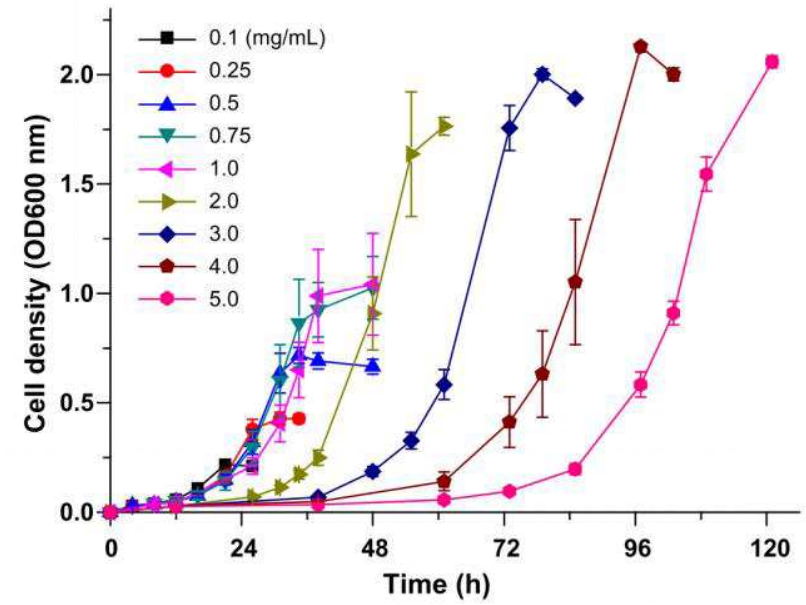

C

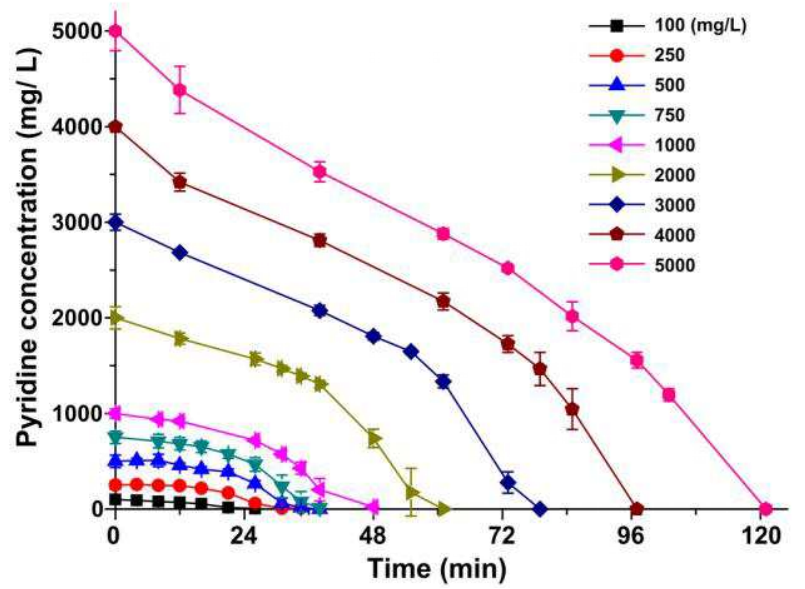

b

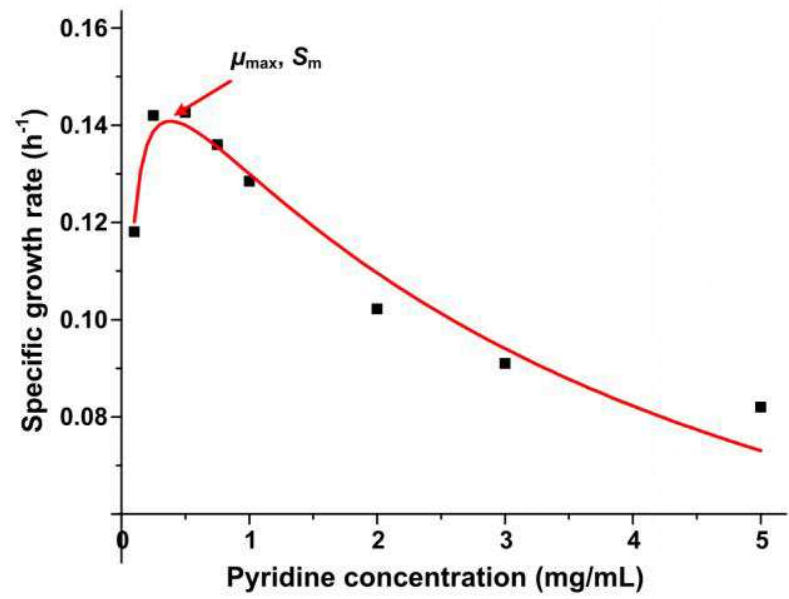

d

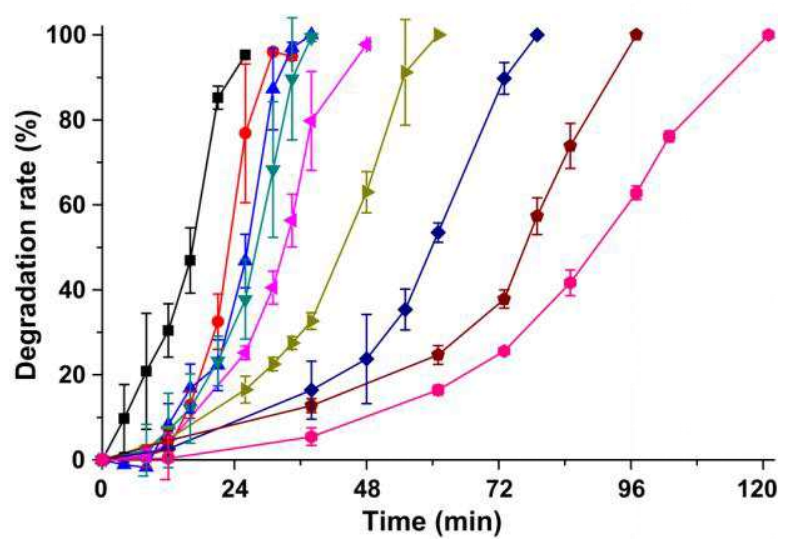


Figure 5

a

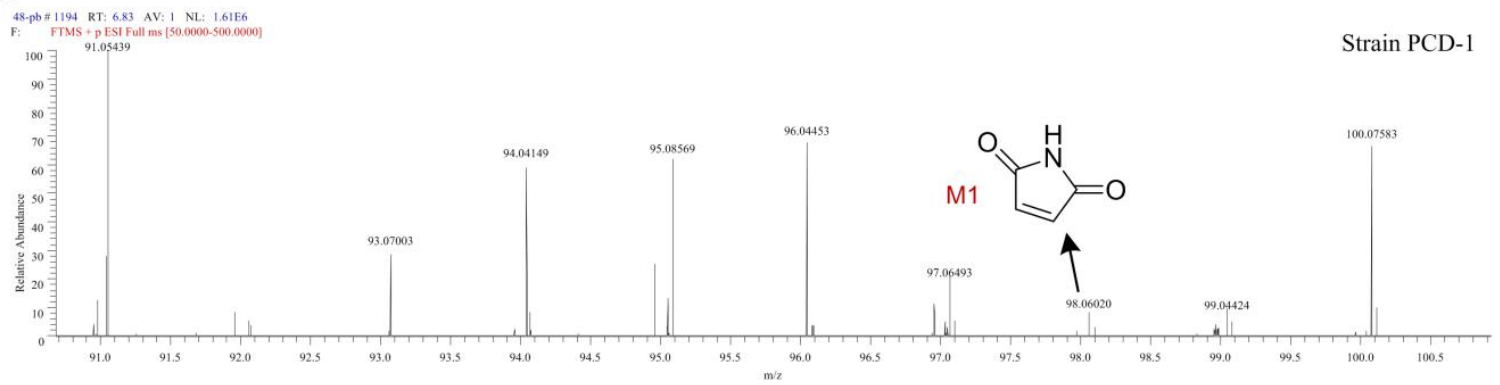

b

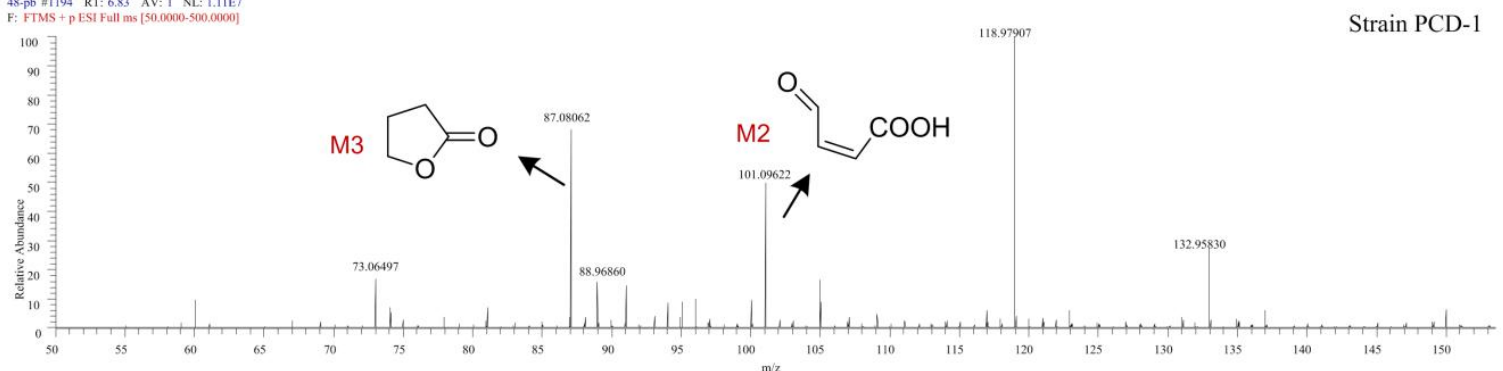

C

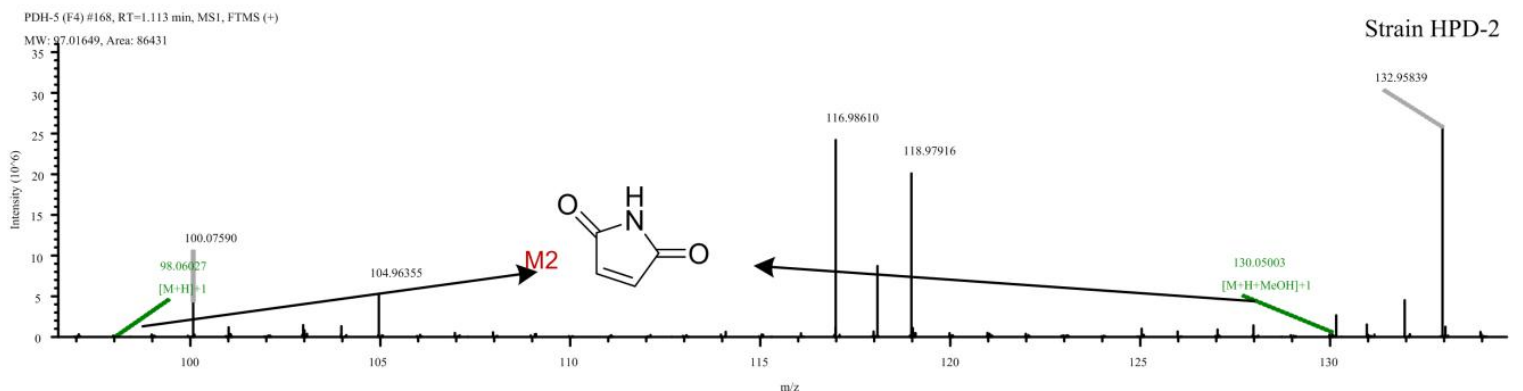

d

PDH-10 (F9) 4166, RT=1.112 $\mathrm{min}, \mathrm{MS} 1$, FTMS (+)

Strain HPD-2

MW: 84.02129 , Area: 188268

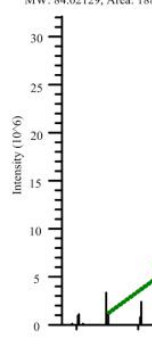


Figure 6

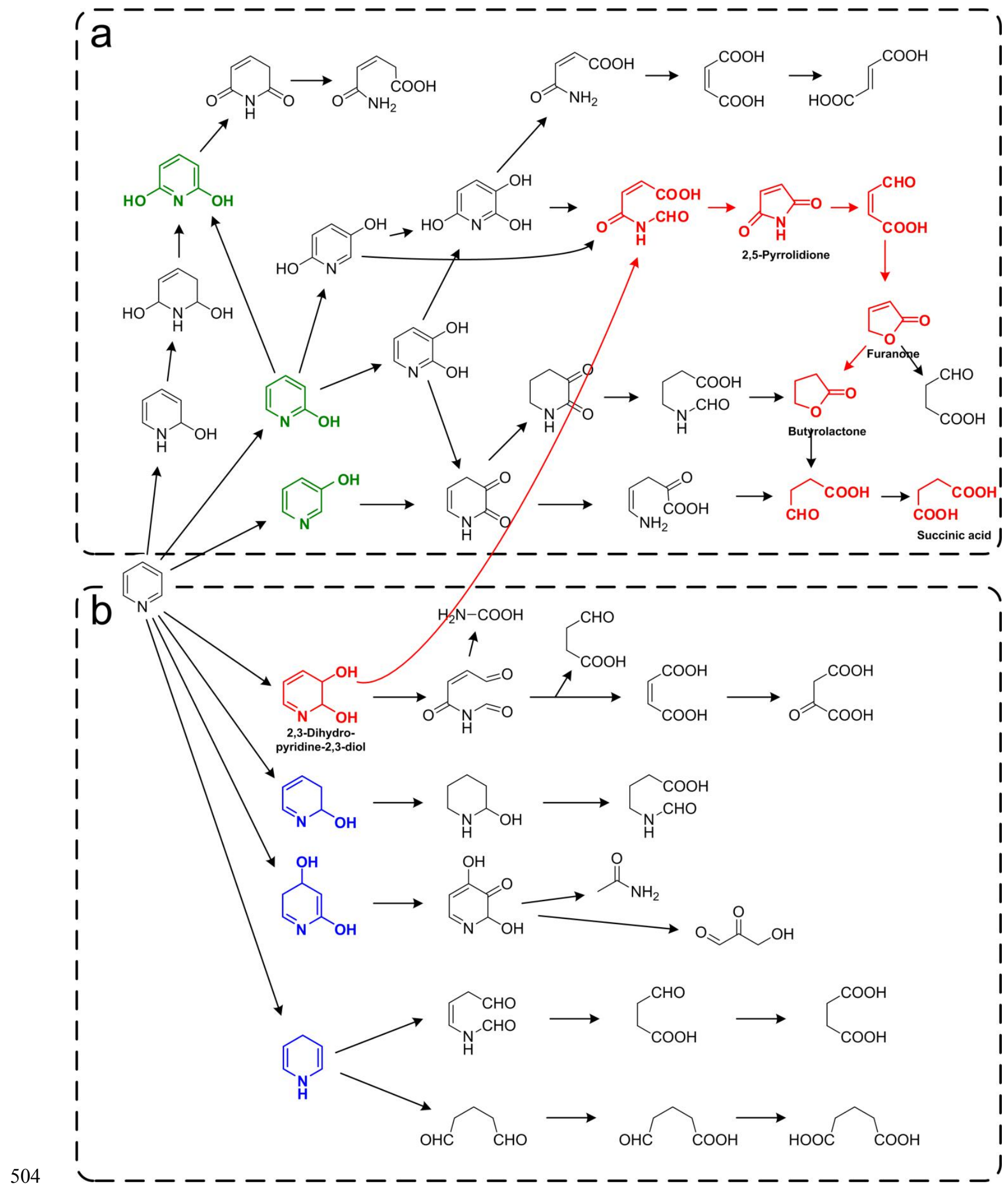


Figures

a

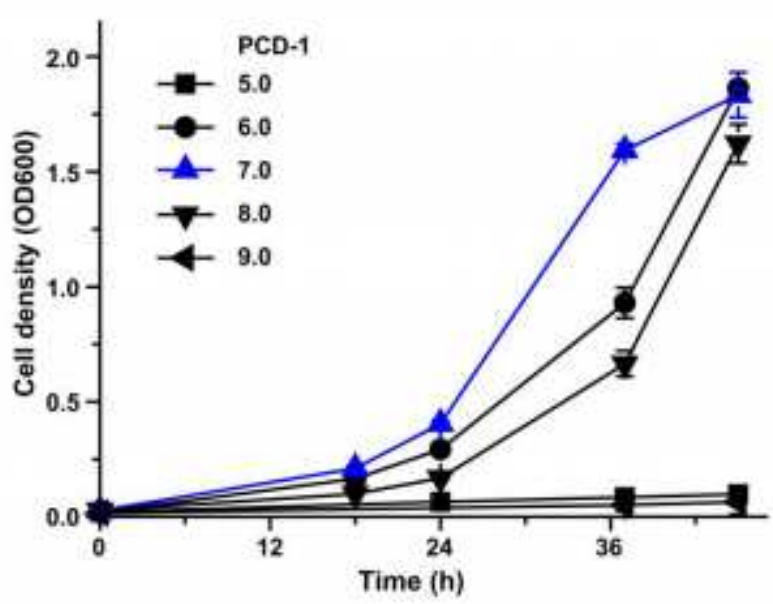

C

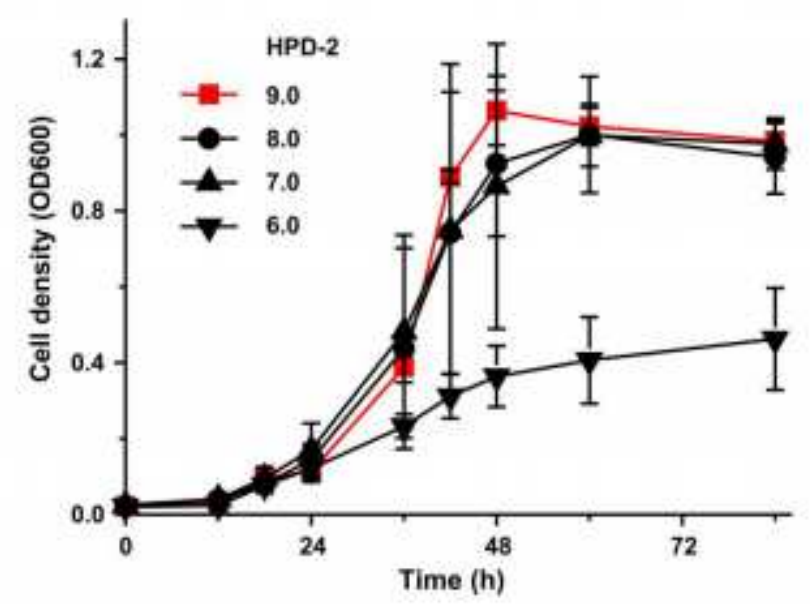

b

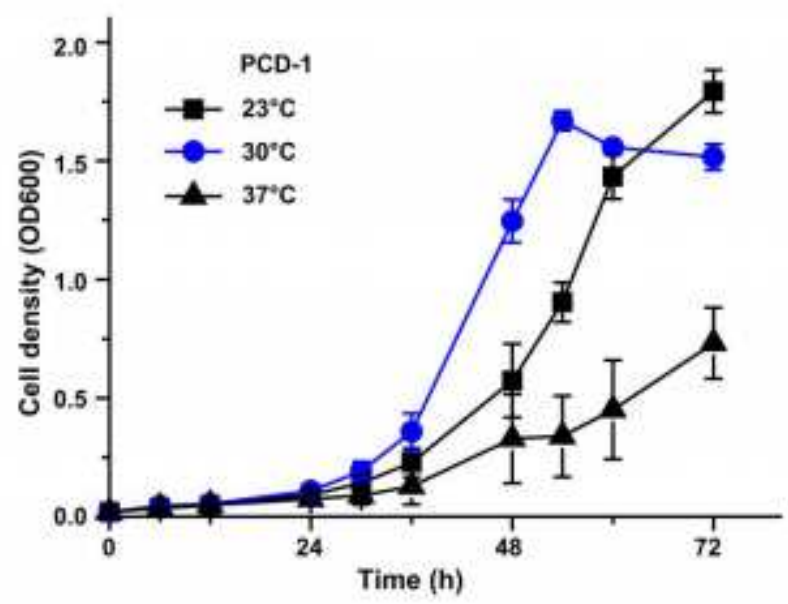

d

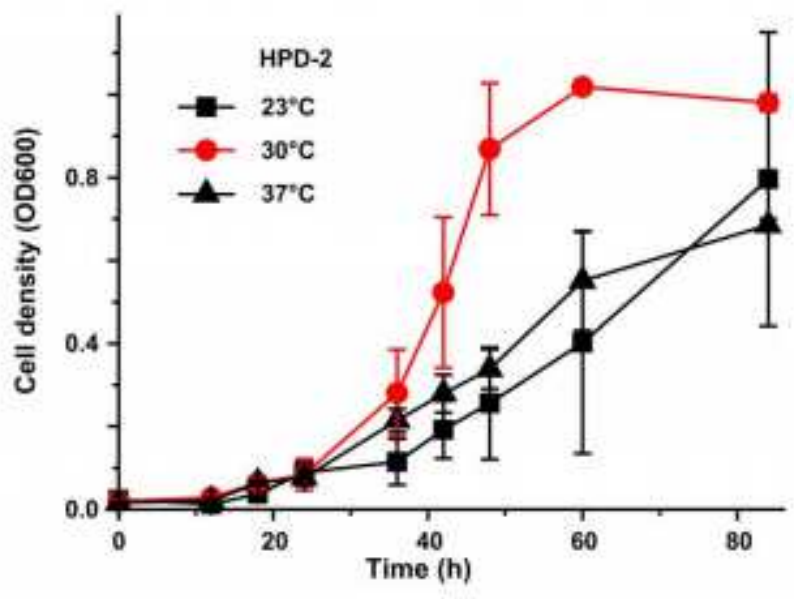

Figure 1

The temperature and $\mathrm{pH}$ influence on PCD-1 and HPD-2 growth were performed in MSM with $1000 \mathrm{mg} / \mathrm{L}$ pyridine. (a) Effects of temperature for growth of strain PCD-1; (b) Effects of pH for growth of strain PCD1 ; (c) Effects of temperature for growth of strain HPD-2; (d) Effects of $\mathrm{pH}$ for growth of strain HPD-2. Each value is the mean from three parallel replicates $\pm S D$. 
a

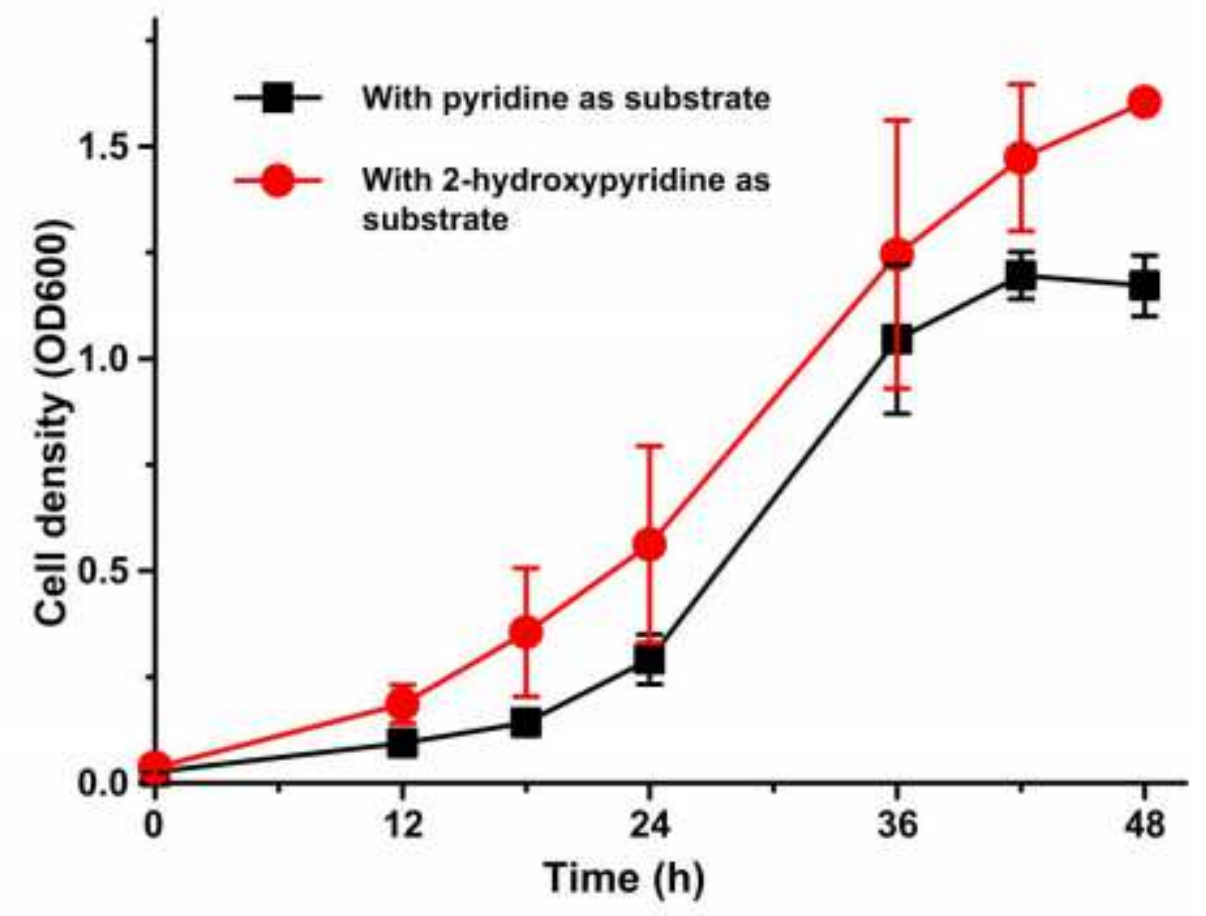

b

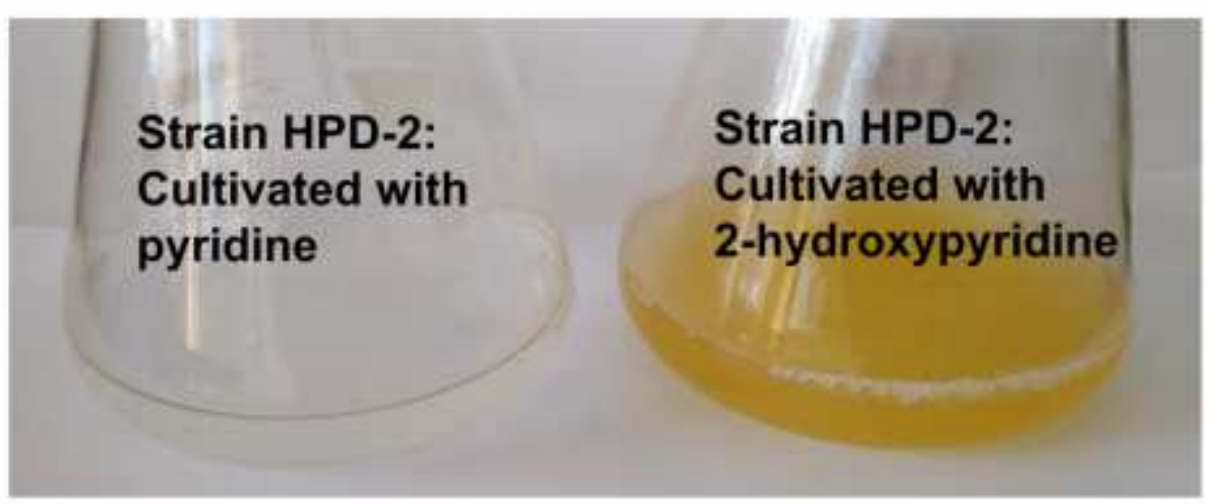

Figure 2

Growth of Rhodococcus sp. strain HPD-2 with 1000 mg/L pyridine and 1000 mg/L 2-hydroxpyridine, respectively. (a) Growth curve of strain HPD-2 with different substrates. (b) Cultures of strain HPD-2 with two different substrates. Each value is the mean from three parallel replicates \pm SD. 


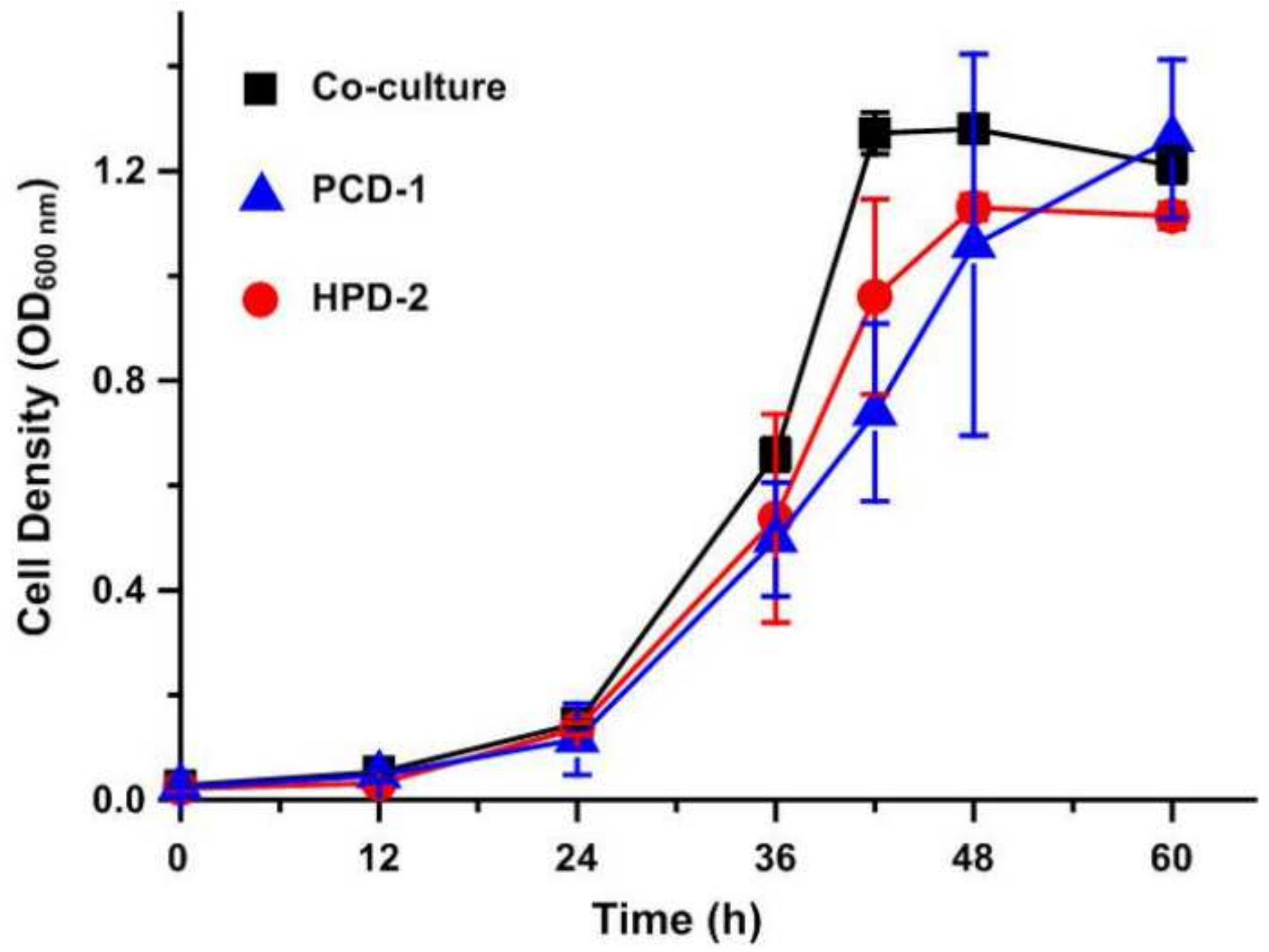

Figure 3

Growth of co-culture CoPD and the individual two strains in MSM with $1000 \mathrm{mg} / \mathrm{L}$ pyridine. Each value is the mean from three parallel replicates \pm SD 
a
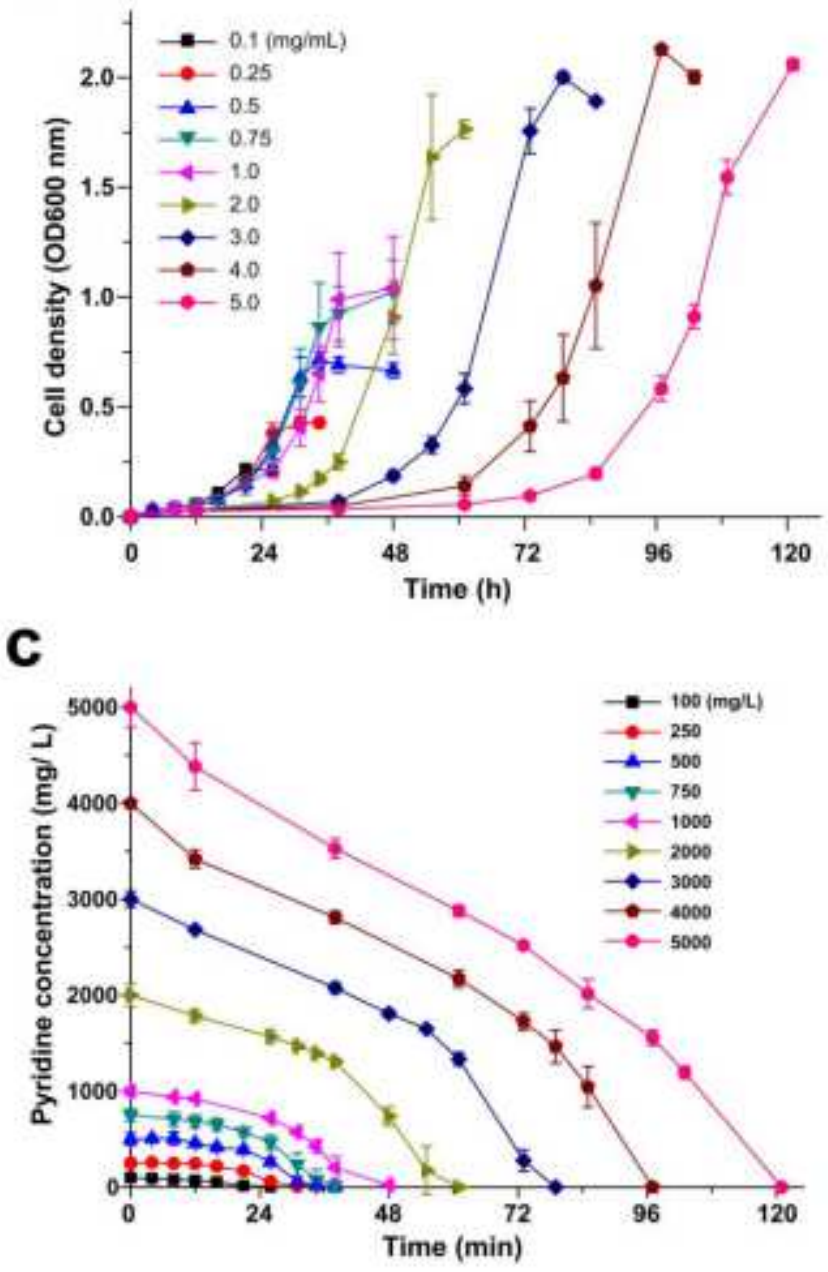

b

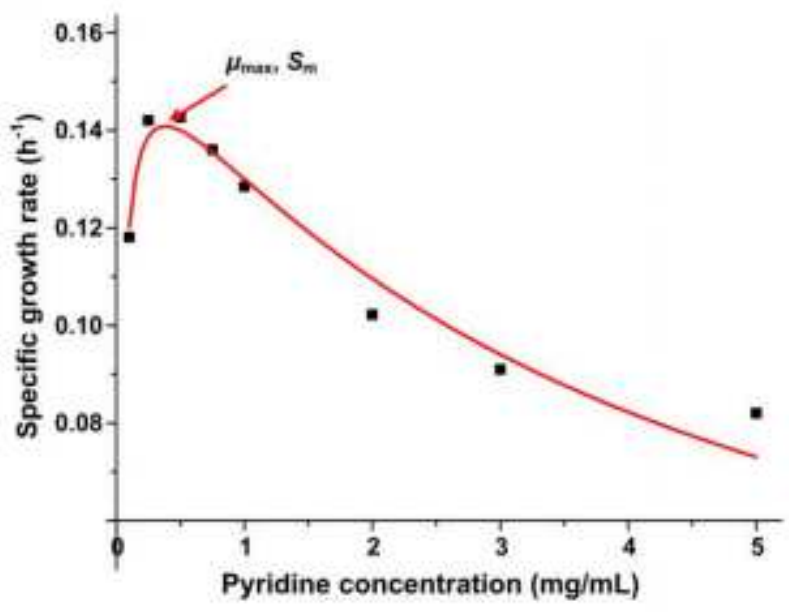

d

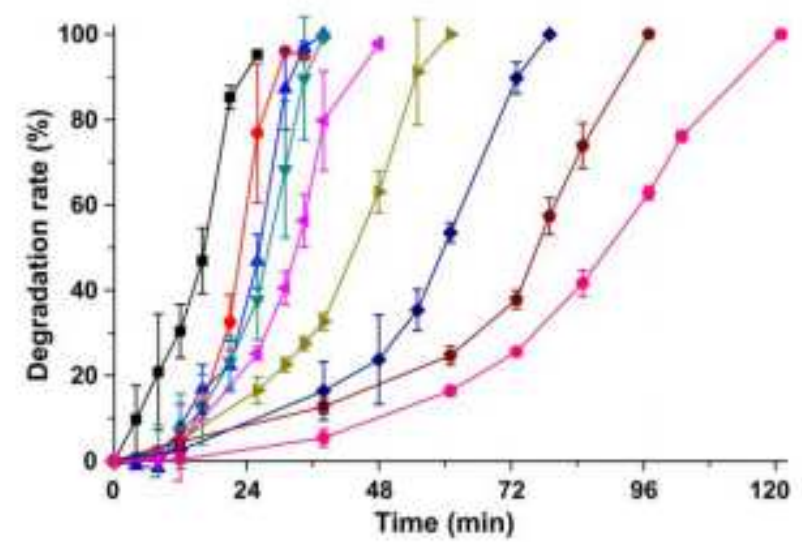

Figure 4

Growth kinetics of co-culture. (a) Effects of pyridine concentration on the growth of co-culture of strain PCD-1 and HPD-2; (b) Haldane's inhibition growth model fitted to results of batch growth experimental data to determine bio-kinetics parameters. (c, d) Effects of initial pyridine concentration on pyridine degradation (c) and degradation rate (d) of co-culture. Each value is the mean from three parallel replicates \pm SD. 
a

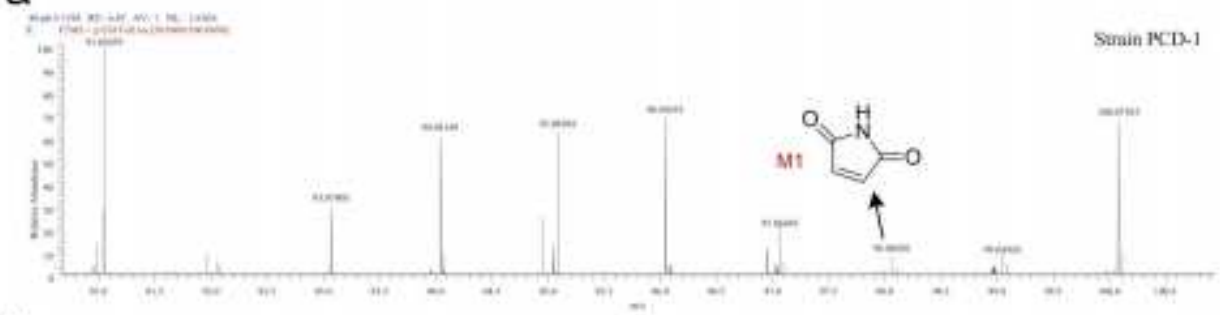

b

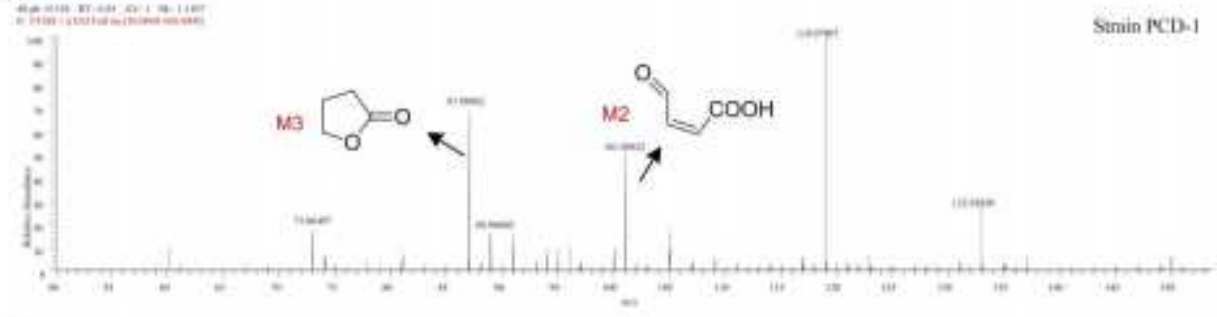

C

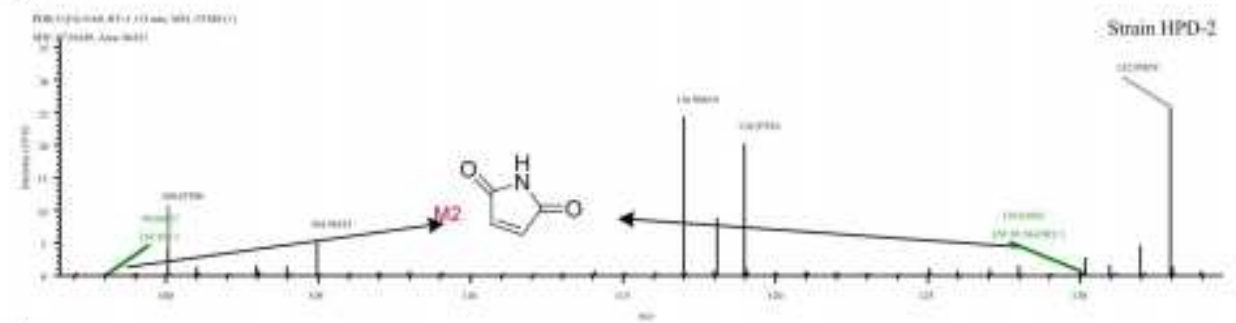

d

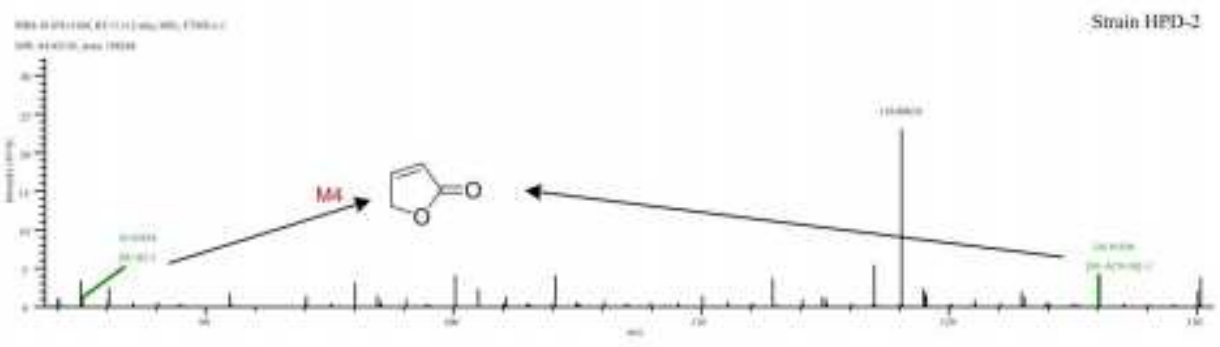

Figure 5

LC-MS analysis of pyridine degradation intermediates of Arthrobacter sp. PCD-1 $(a, b)$ and Rhodococcus sp. HPD-2 (c, d). 


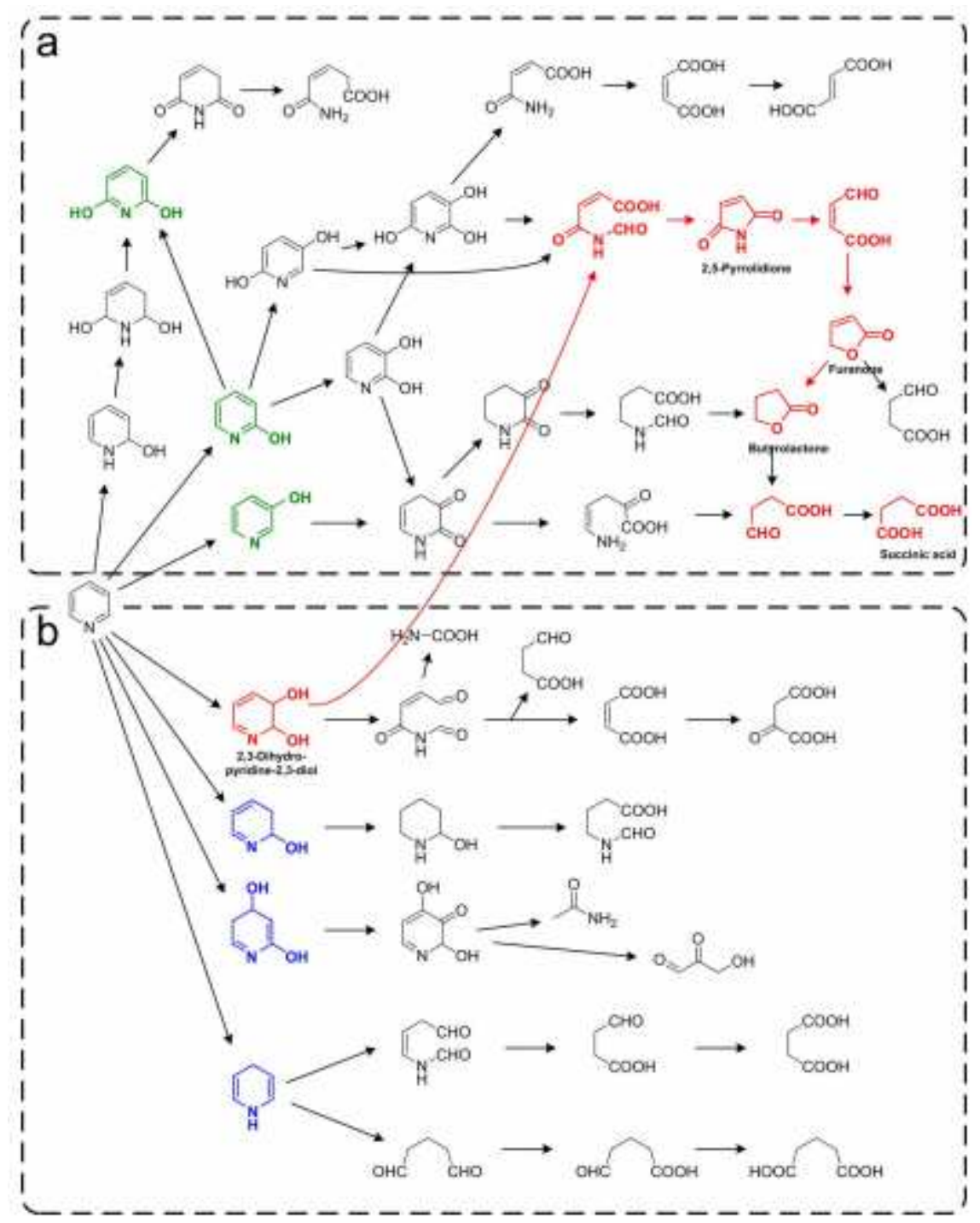

Figure 6

Proposed microbial pyridine degradation pathways. (a) The hydroxylation strategy of pyridine degradation; (b) The dehydrogenation strategy of pyridine degradation. The red structural formulas indicated the proposed degradation pathway in strain PCD-1 and strain HPD-2. 